\title{
АНАЛИЗ ФЛУКТУАЦИИ ФОНОВЫХ СОДЕРЖАНИЙ ХИМИЧЕСКИХ ЭЛЕМЕНТОВ ПРИ ЛИТОХИМИЧЕСКИХ ПОИСКАХ В УСЛОВИЯХ ТРОПИЧЕСКОГО ВЫВЕТРИВАНИЯ. ЮЖНАЯ АМЕРИКА, ГАЙАНА
}

\author{
Соболев Игорь Станиславович1,2, \\ geolsob@yandex.ru \\ Соболева Надежда Петровна, \\ sobnadi@yandex.ru \\ 1000 «Гео Сервис», \\ Россия, 634028, г. Томск, ул. Учебная, 5, офис 21 \\ 2 Тихоокеанский океанологический институт им. В.И. Ильичева ДО РАН, \\ Россия, 690041, г. Владивосток, ул. Балтийская, 43. \\ 3 Национальный исследовательский Томский политехнический университет, \\ Россия, 634050, г. Томск, пр. Ленина, 30.
}

\begin{abstract}
Актуальность работы определяется увеличением информативности литохимических исследований по вторичным ореолам рассеяния в условиях влажного тропического выветривания. Повсеместное развитие мощных коровых покровов создает ограничение для изучения пород фундамента в естественных обнажениях. В такой обстановке возрастает роль геохимических методов при решении задач геологического картирования фундамента и поисков локализованных в нем месторождений полезных ископаемых. Характерной чертой тропического гипергенного перераспределения химических элементов является его высокая интенсивность, общее доминирование выноса с одновременным концентрированием ряда компонентов при латеризации и кирасировании. Сочетание этих процессов приводит к высокой изменчивости геохимического фона и возникновению вторичных аномалий ряда металлов, не имеющих генетической связи с рудными объектами. По этой причине весьма актуальным является ландшафттно-геохимическое картирование. Оно призвано осуществить районирование территорий по особенностям распределения компонентов в элементарных ландшафтах и систематизировать основные причины вариативности геохимического фона. В числовых значениях содержаний химических элементов содержится информация о всей совокупности природных процессов, повлиявших на компонентный состав изучаемого материала. Как следствие, исследование литохимических данных инструментами статистического анализа позволяет получить математическую модель в варианте типологической ландшафртно-геохимической карты.

Цель: осуществить диффреренциацию территории по особенностям изменчивости геохимического фрона.

Методы: многофакторный, корреляционный и кластер-анализ многокомпонентных данных литохимических поисков по вторичным ореолам рассеяния.

Результаты. Получена классификационная модель геохимического фона, отражающая связь уровней накопления химических элементов с геоморфрологическим и геологическим строением; с учетом амплитудных и пространственных характеристик изменчивости геохимического поля во вторичных ореолах рассеяния определены элементь-спутники золоторудной минерализации.
\end{abstract}

\section{Ключевые слова:}

Коры выветривания, химические элементы, классификационная модель, геология, геоморфология, влажнье тропики.

\section{Введение}

Изучение геохимии процессов корообразования в условиях влажного тропического климата не теряет своей актуальности на протяжении многих лет и привлекает внимание многочисленных исследователей [1-9]. Яркой особенностью тропического гипергенеза является формирование латеритных кор выветривания, с которыми связаны крупнообъемные месторождения алюминия, железа, никеля, золота. Обширное площадное распространение и большая мощность коровых покровов существенно затрудняют изучение геологического строения фундамента и выявление в нем рудных месторождений. В связи с этим идентификация типов корообразующих пород и собственно поисков рудной минерализации по вторичным ореолам рассеяния являются весьма актуальными задачами для геохимических исследований $[3,10]$. Сложность использования методов геохимии в условиях ландшафтной зоны влажных тропических лесов обусловлена глубо- кими изменениями минерального состава коренного субстрата, сопровождающимися интенсивным перераспределением компонентов в вертикальном и латеральном профиле кор выветривания. Например, при анализе типа выветрелых пород на основе геохимических индексов некоторые химические элементы, считающиеся малоподвижными, нецелесообразно привлекать для оценки баланса массы и объема [3]. Ландшафты влажных тропиков характеризуются резким сдвигом в сторону выноса суммарного эффекта миграции и аккумуляции химических элементов вследствие доминирования кислого выщелачивания $[1,2,5]$. Гипергенное концентрирование слабых мигрантов главным образом происходит в форме остаточного накопления. Для подвижных компонентов характерно сорбционноинфильтрационное обогащение в условиях активного водообмена, а также их осаждение на динамических, щелочных и восстановительных барьерах в пределах пониженных форм рельефа. Как следствие, местные 
автономные геохимические ландшафты существенно различаются по уровням фонового содержания широкого спектра химических элементов. Распространенное явление - это вторичные аномалии металлов, возникновение которых в большей мере обусловлено геоморфологическими причинами, а не типом пород и наличием рудных объектов.

Реализация литохимических поисков по вторичным ореолам рассеяния без изучения фоновой флуктуаций чревата высоким риском появления прогнозно-поисковых ошибок. Поэтому методическими документами рекомендуется осуществлять анализ ландшафтно-геохимических условий исследуемой территории. Полнота и достоверность ландшафтногеохимического районирования во многом зависит от наличия и качества геологической, геоморфологической, ландшафтной информации, удовлетворяющей масштабу проводимых исследований. Для слабо изученных территорий подобные данные нередко просто отсутствуют. Однако в числовые характеристики распределения химических элементов заложен интегральный эффект влияния природных условий. На этом основывается широкое использование математической статистки для анализа геохимических данных, в том числе при решении задач выделения аномального сигнала в условиях высокоамплитудной изменчивости геохимического фона. Эффективными статистическими инструментами пространственной геологической дифференциации объектов исследований на основе многокомпонентной информации являются способы классификации методами кластеранализа [11]. Даже при сравнительно небольшом количестве вовлеченных в изучение химических элементов удается получить адекватные классификационные модели геологического строения территорий зоны влажных тропиков [12].

\section{Геолого-геоморфологическое строение}

Площадь исследований расположена на Гвианском плоскогорье северо-западной части горной системы Сьера-Пакарайма в Республике Гайана, в зоне произрастания влажных тропических лесов.

$\mathrm{C}$ позиций региональной геологии участок литохимической съемки находится в северной части докембрийского Гвианского щита, являющегося северным сегментом Амазонского кратона в Южной Америке [13-17]. Основные черты геологического строения территории определяются ее положением в пределах палеопротерзойских пород зеленокаменного пояса супергруппы Барама-Мазаруни (рис. 1). Вулканогенноосадочная толща, метаморфизованная в условиях зеленосланцевой и амфиболитовой фаций, интрудирована телами гранитоидного комплекса Транс-Амазонской орогенной серии, а также посторогенными дайковыми поясами, связанными с меловым Атлантическим рифтогенезом. Площадь исследований принадлежит к области тектонического влияния регионального палеопротерозойского сдвига Макапа-Курибронг, с которым сопряжены протяженные линейные зоны дробления и пластической деформации. В пределах этого структурного коридора выявлено большинство известных на сегодняшний день проявлений и месторождений золота $[16,18]$. Находящееся наиболее близко к участку геохимического картирования орогенное месторождение золота Аврора приурочено к одному из ответвлений Транс-Амазонской зоны смятия.

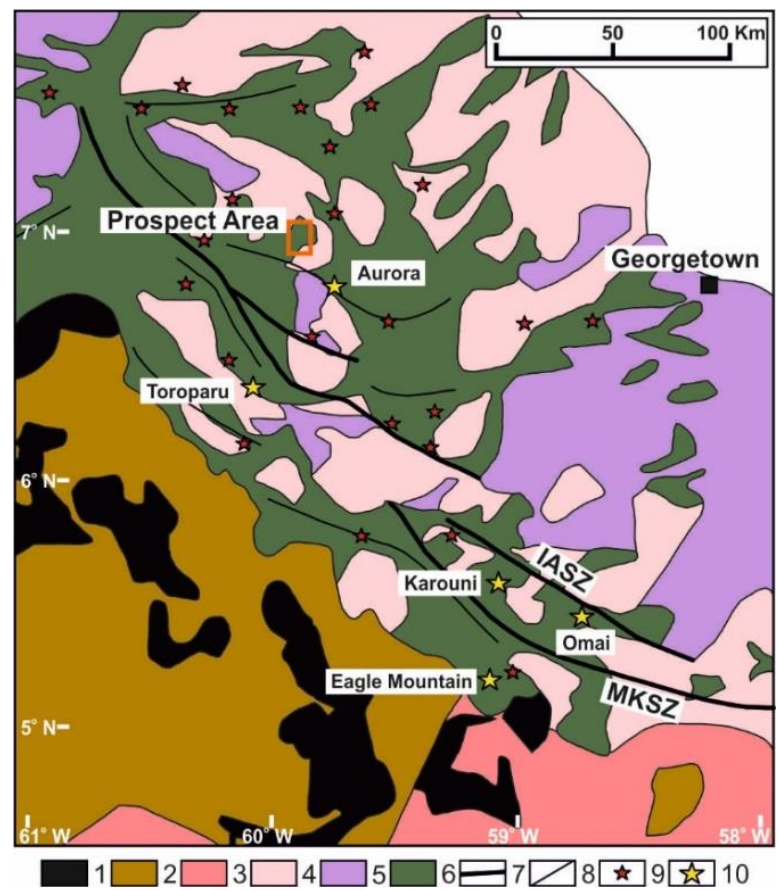

Рис. 1. Геология северной части Гвианского изита с главными золоторудными месторождениями (по M. Tedeschi и дp., 2018 [17]): 1) мафитовые интрузивные породы (1,79 млрд лет и моложе), долериты комплекса Аваневеро и другие протерозойские мафитовые и щелочные интрузии; 2) древний платформенный чехол ( 1,87 млрд лет) Рораяма Супергруппь; 3) древние фельзические вулканиты и гранитоиды пояса Орокайма (1,99-1,95 млрд лет); 4) Транс-Амазонская провинция (2,26-2,09 млрд лет.), «Молодые гранитыл (2,11-2,08 млрд лет); 5) диапировые тоналит-трондьемит-гранодиоритовые интрузии, гнейсы (2,18-2,13 млрд лет); 6) зеленокаменные пояса (2,2-2,1 млрд лет); 7) зона смещения регионального масштаба (IASZ=зона смещуения Иссано-Annanapu, MKSZ=зона смещуения МакапаКурибронг); 8) региональные зоны складчатости; 9) проявления $\mathrm{Au}$; 10) месторождения $\mathrm{Au}$

Fig. 1. Geology of northern part of Guiana Shield highlighting major gold deposits (adapted from $M$. Tedeschi et al., 2018 [17]: 1) mafic intrusive rocks (1,79 Ga and younger), Avanavero dolerite and other proterozoic mafic and alkaline intrusive rocks; 2) older platform cover ( 1,87 Ga) Roraima Supergroup; 3) older felsic volcanic and granitoid belt "Orocaima» (1,99-1,95 Ga); 4) Trans-Amazonian Province (2,26-2,09 Ga), "Younger Granites» $(2,11-2,08 \mathrm{Ga})$; 5) diapiric tonalite-trondhjemitegranodiorite intrusions; gneisses $(2,18-2,13 \mathrm{Ga})$; 6) greenstone belts $(2,2-2,1 \mathrm{Ga})$; 7) regional scale shear zone (IASZ=Issano-Appapari shear zone, MKSZ=Makapa-Kuribrong shear zone); 8) region foliation; 9) Au occurrences; 10) Au deposits 

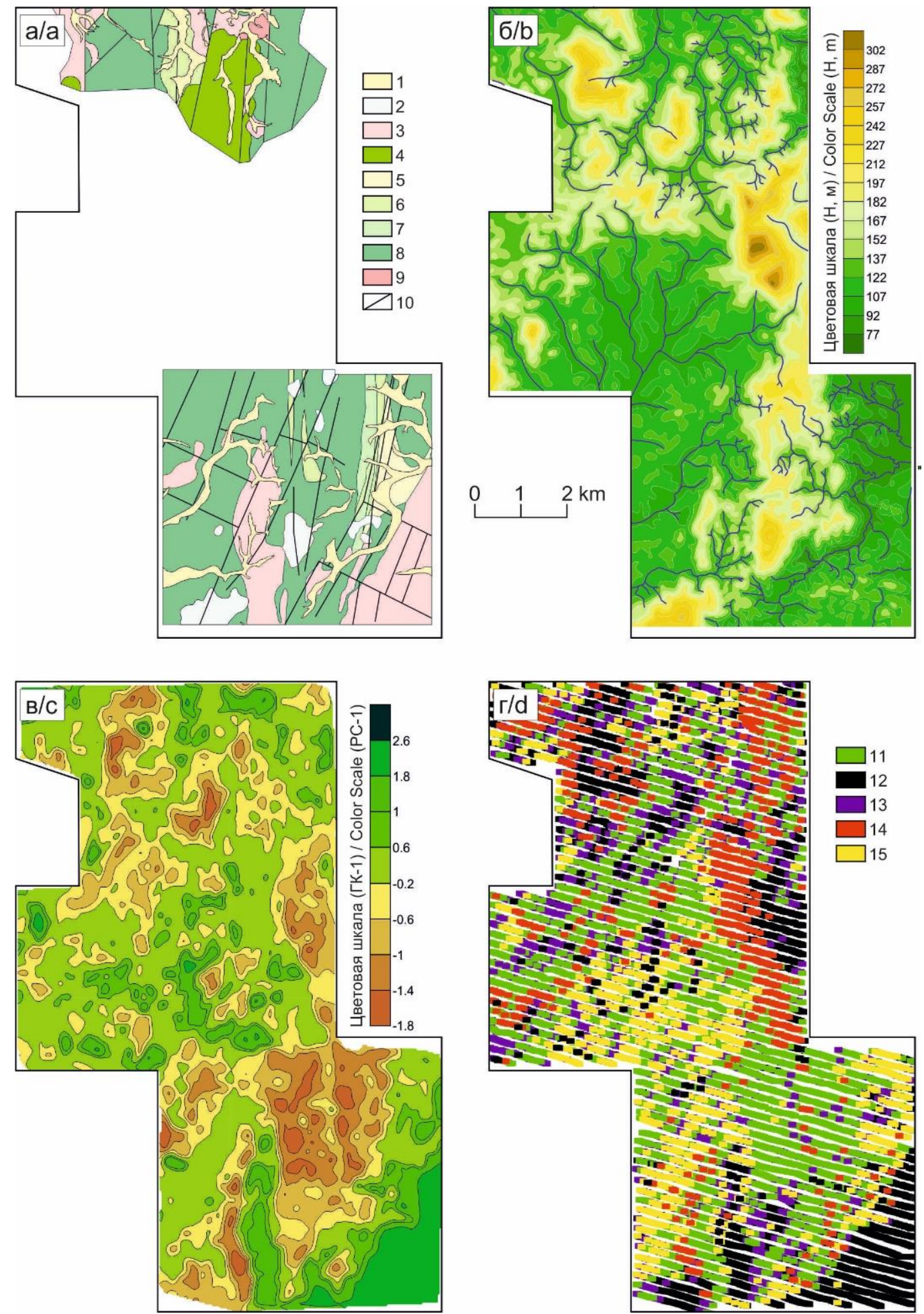

Pис. 2. Геологическое (а) и геоморфологическое (б) строение (по данным ООО «Золотой Запас» и ООО «Зарубежгеология»), влияние ГК-1 (в), схема геохимических квазиоднородных участков (2): 1) аллювиальные четвертичные отложения $(Q)$; 2) латеритные коры выветривания; 3, 4) Транс-Амазонский комплекс $\left(P R_{2}\right):$ гранит биотитовый, амфиболитовый (3), габбро (4); 5-8) формация Куюни $\left(P R_{1}\right):$ нерасчлененные вулканогенно-осадочные породы (5), метавулканиты основного состава (6), амфиболовые гнейсы (7), амфиболиты (8); 9) гранитогнейсы комплекса Иматака (AR); 10) разломы; 11-15) коррелячионные ассоииации кластеров: $A(11), 5-a(12), 5-6(13), B(14), \Gamma(15)$

Fig. 2. Geology (a) and geomorphology (b) (according LLC «Zolotoy Zapas» and LLC «Zarubezhgeologiya»), PC-1 score (c), schematic map of geochemical quasihomogeneous plots (d): 1) alluvial sediments (Q); 2) laterirtic crust; 3, 4) Trans-Amazonian Complex $\left(P R_{2}\right)$ : biotite and amphibolite granites (3), gabbro (4); 5-8) Cuyuni Formation $\left(P R_{1}\right)$ : poorly-defined volcanogenic sedimentary rocks (5), mafic metavolcanics (6), amphibolic gneisses (7), amphibolites (8); 9) gneissose granite Imataca Complex (AR); 10) faults; 11-15) clusters correlation associations: $A$ (11), $B$ - $a$ (12), B-b (13), C (14), D (15) 
Локальная геология площади геохимических исследований изучена неравномерно. По результатам работ ОАО «ВНИИЗарубежгеология» (2012 г.) и ООО «Золотой Запас» (2016-2017 гг.) составлены геологические карты масштаба 1:10000, охватывающие южную и частично северную части территории (рис. 2, a). К породам архейского фундамента, входящим в комплекс Иматака, отнесены единичные выходы гранитогнейсов на севере участка $[19,20]$. Основную часть разреза слагают древние амфиболиты, метавулканиты и метаосадочные породы палеопротерозойской формации Куюни группы Мазаруни. Прорывающие их среднепротерозойские интрузивы Транс-Амазонского комплекса разнообразны по размерам и своему составу. Сравнительно крупные массивы и тела сложной морфологии представлены ультрамафитами, габброидами и гранитами. В разрезе выделяются протяженные зоны, насыщенные телами малых интрузий. Они представлены среднепротерозойскими дайками и штоками средне-кислого состава, а также мезозойскими дайками долеритов и диоритов. На площади исследований закартированы разрывные нарушения нескольких направлений, главными из которых являются системы СВ и С3 простирания. В границах участка выявлены три золотоносные зоны. По основным особенностям локального контроля оруденения они имеют много общего с орогенными золоторудными объектами зеленокаменного пояса супергруппы Барама-Мазаруни $[19,20]$. К ним относят: пространственную ассоциацию с зонами смятия; связь с интрузивными породами основного-среднего состава; приуроченность золота к кварц-карбонат-пиритовым жилам и штокверкам, таблитчатым, брекчиевым и линзообразным телам и тонким прожилкам; соответствие формациям пропилит-филлитовых изменений $[16,18]$. Существенным отличием рудных и околорудных гидротермалитов площади исследований от орогенных месторождений золота зоны сдвига Макапа-Курибронг является невысокое содержание в жилах карбонатов и очень слабое развитие процессов карбонатизации [19, 20].

Мощность кор выветривания зависит от рельефа и в среднем достигает на участке исследований 20-30 м. Обобщенный разрез выветрелого горизонта (сверху вниз) характеризуется следующим образом [19, 20]:

- латериты и «латеритоподобные» бесструктурные глинистые коры выветривания кирпично-красного, буровато-коричневого цвета с дресвой железистых обломков (пизолитов) мощностью от 0,5 до $20 \mathrm{M}$;

- глинистые бесструктурные или со слабо проявленными фрагментами структуры, пятнисто окрашенные коры выветривания мощностью от 1,5 до $8 \mathrm{~m}$;

- структурные глинистые и щебенисто-глинистые коры выветривания мощностью от 4,0 до 10 м;

- глинизированные коренные породы (зона сапролитов) мощностью до 5 м.

В геоморфологическом отношении территория представляет собой низкогорно-холмистую поверхность, прорезанную долинами рек Ирома, Даквари и их более мелкими притоками (рис. 2, б). Геологическое и геоморфологическое строение имеет определенную связь. Гранитоидные массивы слагают выровненные и пониженные формы рельефа, примыкающие к мелким горам, сложенным преимущественно амфиболитами.

\section{Литохимическое опробование}

Литохимическое опробование проводилось силами ООО «Золотой Запас» по сети 40 на 200 м в 2016 (южный сектор) и 2017 (северный сектор) гг. Терригенный материал весом 0,2-0,3 кг отбирался из подпочвенного горизонта с глубины 0,2-0,6 м. Координатная привязка пунктов опробования осуществлялась навигационными приемниками GPSmap60C. В полевом лагере материал пробы просушивался и просеивался через сито с размером ячеи 1 мм. Концентрации широкого спектра химических элементов, включая золото, определялись методом ИСП-МС в лабораториях г. Джорджтаун, Гайана: Act Labs (2016 г.) и MS Analytical (2017 г.).

\section{Обработка и интерпретация данных}

Качество результатов испытаний проб двух участвовавших в исследованиях лабораторий существенно отличается. Поэтому предобработка велась раздельно для двух массивов литохимических данных, принадлежащих южному и северному секторам опробования. Из анализа исключалась информация по химическим элементам со значительной долей результатов измерений, находящихся ниже порога чувствительности лабораторного определения. Дальнейшая оценка параметрических и непараметрических характеристик распределения случайных величин показала, что наиболее адекватно ожидаемому положению отвечает геометрическое среднее значение. Для увязки результатов лабораторных испытаний разных лет проведено нормирование значений концентраций химических элементов с использованием их геометрических средних. После этой процедуры выборки были объединены. С целью предотвращения появления ложных корреляций, возникающих в замкнутых системах процентных величин, осуществлена CLR (Centred LogRatio) трансформация данных [21, 22].

Золото значимо не коррелирует ни с одним химическим элементом. По этой причине, а также из-за желания избежать его влияния на результаты статистического анализа многокомпонентной информации, оно было исключено из расчетов на стадии оценки особенностей флуктуации геохимического фона.

С целью сокращения количества изучаемых признаков выполнен многофакторный анализ методом главных компонентов. В модель были включены главные компоненты с собственными значениями $\geq 1$ в сумме описывающие 82,8 \% общей дисперсии (таблица).

Первый главный компонент $(Г K-1)$ представлен ассоциацией щелочных и щелочноземельных элементов с изоморфно входящим в состав бариевых и стронциевых минералов La, a также примкнувшими к ним W и Zn. В пространственном распределении фак- 
торного влияния отмечается ярко проявленная тенденция (рис. 2, в). Она выражается в обособлении областей высоких значений в пределах пониженных форм рельефа, особенно по долинам рек и заболоченным участкам. Снижение числового параметра воздействия $\Gamma K-1$ происходит по мере роста высотных отметок отбора проб, достигая отрицательных значений в пределах местных водоразделов. Примыкание $\mathrm{W}$ и отчасти $\mathrm{Zn}$ к группе элементов $Г K-1$ обусловлено тем, что крупные тела гранитоидов, участвующие в геологическом строении территории, расположены на низких гипсометрических уровнях.

Таблица. Врамаемые факторные нагрузки в пятифакторной модели геохииического поля (10293 пробы; красным выделены нагрузки $\geq 0,6$ )

Table. $\quad$ Rotated factor loadings in five-factors models of geochemical spatial patterns (10293 samples; marked in red loadings are $\geq 0,6)$

\begin{tabular}{|c|c|c|c|c|c|}
\hline $\begin{array}{c}\text { Элементы } \\
\text { Elements }\end{array}$ & ГК/PC-1 & |ГК/PC-2 & |ГК/PC-3 & ГК/PC-4 & ГК/PC-5 \\
\hline $\mathrm{Ag}$ & 0,299 & 0,792 & 0,033 & 0,141 & 0,089 \\
\hline $\mathrm{Al}$ & 0,465 & 0,621 & 0,447 & 0,036 & $-0,027$ \\
\hline As & 0,239 & 0,863 & 0,102 & 0,095 & 0,011 \\
\hline $\mathrm{Ba}$ & 0,856 & 0,152 & $-0,232$ & 0,007 & $-0,106$ \\
\hline $\mathrm{Bi}$ & 0,508 & 0,724 & 0,001 & 0,097 & 0,140 \\
\hline $\mathrm{Ca}$ & 0,829 & 0,191 & $-0,007$ & 0,147 & 0,286 \\
\hline Co & 0,142 & $-0,832$ & 0,126 & 0,036 & $-0,237$ \\
\hline $\mathrm{Cr}$ & 0,014 & 0,439 & $-0,151$ & 0,786 & 0,110 \\
\hline $\mathrm{Cu}$ & $-0,061$ & $-0,054$ & 0,851 & 0,102 & 0,016 \\
\hline $\mathrm{Fe}$ & $-0,110$ & 0,718 & 0,598 & $-0,023$ & 0,039 \\
\hline $\mathrm{Ga}$ & 0,342 & 0,699 & 0,493 & $-0,106$ & $-0,022$ \\
\hline $\mathrm{La}$ & 0,875 & 0,040 & 0,117 & $-0,027$ & $-0,058$ \\
\hline $\mathrm{Mg}$ & 0,848 & 0,089 & 0,016 & 0,211 & 0,173 \\
\hline $\mathrm{Mn}$ & 0,212 & $-0,503$ & 0,721 & 0,587 & 0,126 \\
\hline Mo & 0,268 & 0,811 & 0,144 & $-0,045$ & 0,015 \\
\hline $\mathrm{Na}$ & 0,776 & 0,486 & $-0,052$ & 0,149 & 0,223 \\
\hline $\mathrm{Ni}$ & 0,368 & $-0,209$ & 0,277 & 0,802 & $-0,069$ \\
\hline $\mathrm{Pb}$ & 0,588 & 0,598 & 0,059 & 0,014 & $-0,245$ \\
\hline $\mathrm{Sb}$ & 0,486 & 0,769 & 0,021 & 0,178 & 0,138 \\
\hline Sc & $-0,098$ & 0,177 & 0,900 & 0,011 & 0,050 \\
\hline $\mathrm{Se}$ & 0,226 & 0,867 & 0,212 & 0,026 & 0,000 \\
\hline $\mathrm{Sr}$ & 0,845 & 0,278 & $-0,026$ & 0,000 & 0,036 \\
\hline Th & 0,529 & 0,758 & 0,160 & 0,007 & $-0,148$ \\
\hline $\mathrm{Ti}$ & 0,266 & 0,094 & 0,103 & 0,018 & 0,897 \\
\hline $\mathrm{Tl}$ & 0,778 & 0,498 & $-0,082$ & 0,141 & 0,176 \\
\hline $\mathrm{V}$ & $-0,341$ & 0,509 & 0,620 & $-0,018$ & 0,060 \\
\hline $\mathrm{W}$ & 0,693 & 0,563 & $-0,009$ & 0,193 & 0,199 \\
\hline $\mathrm{Zn}$ & 0,601 & 0,082 & 0,610 & 0,072 & 0,075 \\
\hline $\begin{array}{l}\text { Общая дисперсия } \\
\text { Total variance, \% }\end{array}$ & 48,0 & 16,3 & 9,5 & 5,0 & 4,0 \\
\hline
\end{tabular}

Примечание/Note: ГК - главный компонент/PC - principal component

Существенная роль геоморфологии в формировании химического состава кор тропического выветривания статистически выражается в значимой парной ранговой корреляции между высотными отметками $(H, \mathrm{м})$ и влиянием факторов. Исключение составляет распределение ГК-5. Корреляция существует, несмотря на невысокую точность гипсометрического позиционирования с помощью GPS-приемников данного класса. Максимальное значение коэффициента ранговой корреляции $\mathrm{R}=-0,42$ принадлежит паре $H-(\Gamma K-1)$.
В ассоциации с ГК-2 находятся химические элементы-маркеры геохимических процессов, протекающих при формировании латеритов, сопровождающихся концентрированием $\mathrm{Fe}$ и $\mathrm{Al}[1,2,5]$. Также положительной корреляцией с $Г К-2$ связаны элементы-гидролизаты - Ga, Th, и сорбирующиеся на гидроокислах железа и алюминия анионогенные элементы - As, Mo, Se, Sb. Интенсивное выщелачивание Co на хорошо промываемых возвышенных участках обусловило его отрицательную корреляцию со вторым главным компонентом. Сопоставление поля распределения значений факторного влияния с геологическим и геоморфологическим строением территории позволило выделить следующие особенности. Наиболее контрастные ореолы положительных значений параметра соответствуют местным водораздельным поверхностям с хорошо развитой кирасой. Слабоконтрастные области положительного воздействия $Г K-2$ в пространстве приурочены к телам гранитоидов Транс-Амазонского комплекса, занимающим пониженные формы рельефа. При этом, в сравнении с кирасами, вторичные ореолы Транс-Амазонских интрузивов обогащены $\mathrm{Ag}, \mathrm{Bi}$, Th и обеднены Fe.

По мнению С.Л. Шварцева и др. [5] процесс латеритного выветривания следует разделять на две части: латеризацию и кирасирование. При латеризации в результате выноса из горной породы подвижных компонентов происходит относительное концентрирование и абсолютный привнос $\mathrm{Fe}, \mathrm{Al}$, Ti и ряда других элементов на фоне общего уменьшения плотности продуктов выветривания. Кирасирование сопровождается инфильтрационным накоплением элементов-гидролизатов в пористых проницаемых породах с последующим увеличением их плотности и формированием отвердевшего горизонта. Низинный тип коры выветривания по гранитоидам и гранитогнейсам характеризуется преимущественно глинистым составом и отсутствием кирасы. Однако самый верхний горизонт обычно окрашен гидроксидами железа и алюминия в бурый цвет. К тому же в условиях интенсивного промывания возможно развитие непосредственно по полевым шпатам гиббсита вместо каолинита [5]. Анализ химического состава кор выветривания на золоторудном месторождении Омаи, расположенном в пределах зеленокаменного пояса Барама-Мазаруни, продемонстрировал, что сильно выветрелые породы все равно в какой-то мере сохраняют геохимический облик материнского субстрата [3]. По всей видимости, существующие отличия в компонентом составе ореолов положительных значений факторного воздействия ГК-2 обусловлены не только особенностями геохимии процессов латеризации и кирасирования в пониженных и повышенных формах рельефа соответственно, но и типом материнских пород.

Ореолы положительного влияния фактора $Г K-3$ слагают протяженные узкие зоны преимущественно CВ и С3 направления. Они трассируют пояса даек основного и среднего состава, наиболее ярко проявленные в распределении $\mathrm{Cu}$ и $\mathrm{V}$. В рельефе эти геохимические линейные неоднородности вытягиваются 
по кирасированным вершинам и крутым склонам местных водоразделов.

Пространственная структура поля параметра влияния $\Gamma K-4$, коррелирующего с распределением $\mathrm{Cr}$ и $\mathrm{Ni}$, дифференцирует территорию по геологическому строению. На разных гипсометрических уровнях ореолами положительных значений контролируются геологические блоки, отнесенные к формации Куюни, имеющей преимущественно мафический состав. Слабо- и среднеинтенсивные отрицательные ореолы маркируют места внедрения гранитоидных интрузивов. Контрастные негативные и резко очерченные линейные зоны ярко проявляют дайковые пояса.

С ГК-5 значимо корреляционно связан только один химический элемент - Ті. Положительными значениями факторного влияния очерчиваются пониженные формы рельефа в пределах распространения палеопротерозойской метаморфизованной толщи. Фрагментами в протяженных зонах внедрения малых интрузий также появляются ореолы положительных значений, но линейного морфотипа. Последние, предположительно, охотнее располагаются на участках развития мафитовых даек, характеризующихся высоким содержанием $\mathrm{TiO}_{2}$ [17].

По значениям влияния $Г K-1$ осуществлена косвенная классификация геоморфологических условий
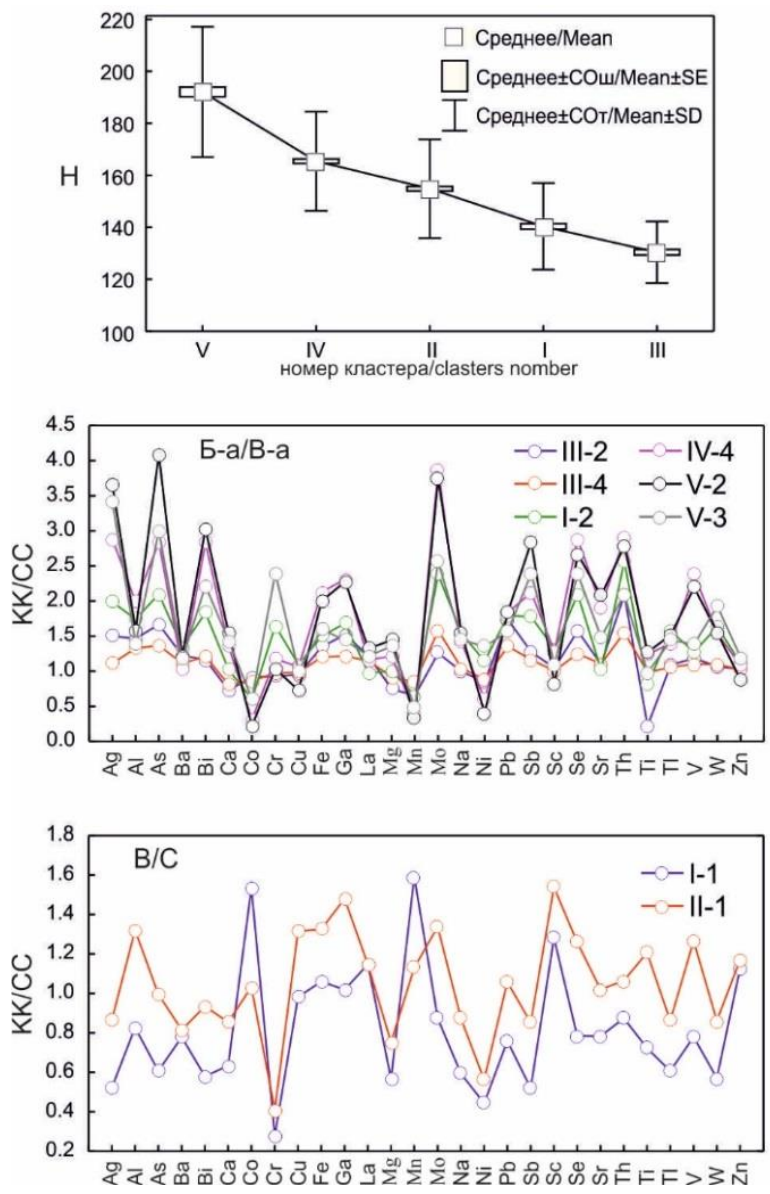

литохимического опробования. Для этого использовался кластерный анализ методом $K$-средних. Количество кластеров подбиралось эмпирически путем последовательного перебора и в итоге составило пять $(\mathrm{CL}-\mathrm{I}, \mathrm{II} . . \mathrm{V})$. Значимость различий между кластерами контролировалась непараметрическим однофакторным дисперсионным анализом и медианным тестом. Таким образом удалось провести геохимическую привязку пунктов опробования к диапазонам гипсометрического уровня (рис. 3). Выборки, сформированные согласно номерам CL, вновь кластеризовались по амплитудам коэффициента влияния $Г K-2$,

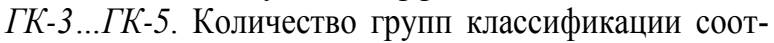
ветствовало числу участвующих в расчете главных компонентов - четырем $(\mathrm{cl}-1,2 \ldots 4)$. Задачей повторной кластеризации являлась дифференциация геохимического поля в зависимости от типа коренного субстрата. По итогам кластерного анализа кодировка проб приняла вид - CL-cl: I - 1, 2, 3, 4...V - 1, $2,3,4$. На основе этой классификации удобно проводить статистическую оценку уровня геохимического фона и расчет минимальных аномальных значений концентраций химических элементов на участках с различными геоморфологическими и геологическими условиями.


Рис. 3. Графики средних значений высотных отлеток (H, м) кластеров факторного влияния ГК-1 и КК корреляционных ассоциаиий кластеров

Fig. 3. Graphs of means elevations $(H, m)$ of clusters PC-1 factor scores and coefficient concentrations $(C C)$ of clusters correlation associations 
С целью прогноза геологического строения территории проведена оценка геохимической специализации выделенных групп проб по значениям коэффициента концентрации (KK):

$$
\mathrm{KK}_{\mathrm{i}}(\mathrm{CL}-\mathrm{cl})=\overline{\mathrm{X}}_{\mathrm{i}}(\mathrm{CL}-\mathrm{cl}) / \overline{\mathrm{X}}_{\mathrm{i}}(\mathrm{CL}),
$$

где $\mathrm{KK}_{\mathrm{i}}(\mathrm{CL}-\mathrm{cl})-$ коэффициент концентрации $i$-го элемента в выборке по признаку классификации CL-cl; $\overline{\mathrm{X}}_{\mathrm{i}}(\mathrm{CL})$ - среднее геометрическое содержание $i$-го элемента для выборки по признаку классификации $\mathrm{CL} ; \overline{\mathrm{X}}_{\mathrm{i}}(\mathrm{CL}-\mathrm{cl})$ - среднее геометрическое содержание $i$-го элемента для выборки по признаку классификации CL-cl.

Состав коренного субстрата, по которому происходит формирование кор выветривания, может быть схожим для разных форм рельефа. В свою очередь, это определяет возможность схожей геохимической специализации проб, отобранных на различных гипсометрических уровнях. К тому же важно подчеркнуть, что влияние геоморфологического фактора на миграцию и накопление компонентов ранее уже ослаблено при расчете коэффициентов концентраций на первом этапе классификации (CL). Чтобы выявить участки с близкими особенностями поведения химических элементов и сократить количество групп итоговой дифференциации территории по особенностям их фоновой флуктуации в пределах гетерогенных геологических блоков проанализирована ранговая корреляция Спирмена. В качестве входных данных использовались средние геометрические значения коэффициентов концентраций, рассчитанные для выборочных совокупностей по признаку CL-cl. Сильными положительными связями $(\mathrm{R} \geq 0,7)$ обособляются четыре генерализованные геохимические ассоциации, одна из которых осложнена относительно слабо коррелирующей с ней пары (рис. 4).

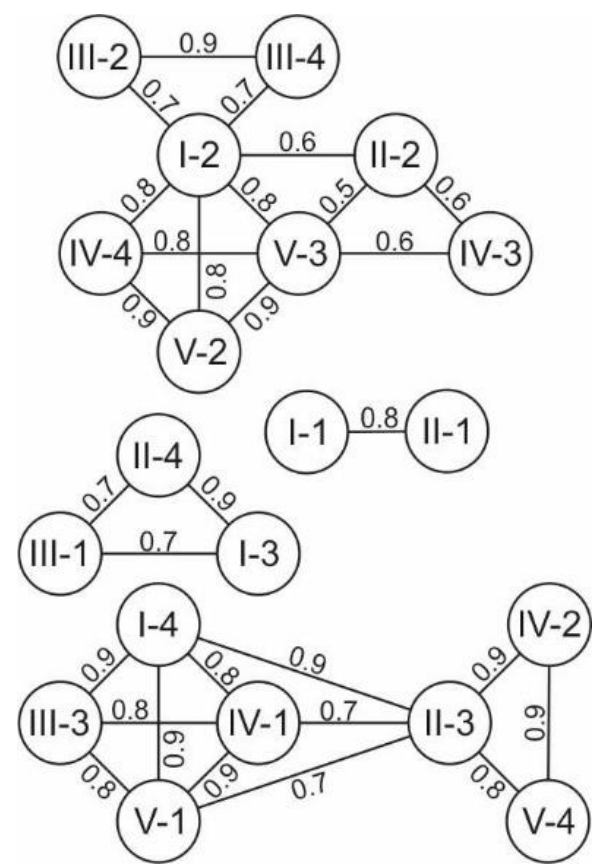

Pис. 4. Графы корреляционных ассоцииций кластеров

Fig. 4. Graphs of clusters correlation associations
По особенностям сигнатур графиков коэффициентов концентраций возможен прогноз типового состава пород фундамента. Группа $A$ по спектру концентрирующихся компонентов близка к мафическим, а ассоциация 5 - $a$ - к средним и кислым породам (рис. 2, 2, рис. 3). Резко обедненные $\mathrm{Cr}$ и Ni образцы $(B)$ принадлежат зонам внедрения среднекислых даек в меланократовые геологические блоки. Группа $Б$-б смешанного состава представлена элементамииндикаторами нескольких типов пород, а в пространстве близка к контактам гранитоидных интрузий либо к линейным зонам, по всей видимости, также проявляющих дайковые комплексы. Образцы ассоциации $\Gamma$ преимущественно локализуются в пониженных формах рельефа в границах вулканогенно-осадочных образований формации Куюни.

\section{Обсуждение результатов}

Анализ литохимических данных подтверждает давно установленный факт, что важное значение при формировании химического состава кор выветривания во влажных тропиках имеет геоморфология, определяющая характер водного режима и как следствие физико-химические параметры среды $[1,2,4,5]$. В результате выщелачивания горных пород на большую глубину в процессы миграции включаются подвижные соединения с одновременным относительным обогащением инертными элементами, а также инфильтрационным «легированием» $\mathrm{Fe}-\mathrm{Al}$ конкреционного горизонта и кирас. В условиях активного водообмена повышенных форм рельефа из пород всех типов наиболее интенсивно выносятся щелочные и щелочноземельные элементы. Их вторичная аккумуляция происходит на глинистых минералах и гумусе в условиях заболоченных впадин, где главным образом формируется низинный каолинитовый тип коры выветривания. Ярко выраженная геоморфологическая зависимость миграции и накопления этих компонентов при слабой связи с минеральным составом фундамента позволяет статистически адекватно осуществить геохимическую привязку образцов грунта к гипсометрическим уровням опробования.

Верхний горизонт вертикального профиля кор выветривания, из которого производился отбор образцов, подвержен существенному влиянию процессов латеризации и кирасирования, приводящих к выравниванию химического состава почв и кор выветривания. Глубокая трансформация минерального состава материнских пород фундамента при тропическом корообразовании существенно затрудняет выявление связей вторичных ореолов рассеяния с коренным субстратом и идентификацию искомых объектов в геохимическом поле $[16,18]$. Тем не менее в результате геохимической дифференциации образцов по геоморфологическому признаку удается осуществить статистическую классификацию проб, несущую информацию о геологическом строении территории. Сравнение сигнатур графиков кларков концентраций различных типов пород, рассчитанных относительно кларков содержания химических элементов в Земной 
коре, и коэффициентов концентрации ассоциаций кластеров позволяет как минимум различать лейко- и меланократовые геологические блоки. К тому же, в конкретном случае возможен прогноз положения дайковых поясов, часто маркирующих зоны смятия. В итоге пространственная геохимическая локализация квазиоднородных участков подчеркивает тектоническое строение территории, обусловленное сочленением двух крупных разноориентированных геологических структур СВ и С3 простирания (рис. 2, г). В представленной классификации участки распространения гранитоидов, тяготеющие к понижениям в рельефе, и кирасированные водораздельные поверхности, сложенные амфиболитами, принадлежат одной ассоциации кластеров - 5 - $a$. Однако они легко разделяются в более дробных характеристиках: III-2 и III-4 - пробы, отобранные в пределах крупных батолитов; I-2 - средние и малые гранитоидные интрузии; IV-4, V-2 и V-3 - кирасы. При этом по результатам сравнительных статистических тестов вторичные ореолы гранитоидов и кирас существенно различаются по характеристикам ожидаемого положения и рассеяния содержаний большинства химических элементов, кроме $\mathrm{Cu}, \mathrm{La}, \mathrm{Pb}$ и $\mathrm{Zn}$.

В поисковой геохимии особенности распределения химических элементов в зоне гипергенеза описываются в рамках исследований элементарных геохимических ландшафтов. Известен факт, что амплитуда флуктуации геохимического фона, обусловленная ландшафтным строением территорий, может превосходить по своим значениям концентрирование рудных компонентов во вторичных ореолах рассеяния месторождений полезных ископаемых [2]. Недостаточное внимание к этому моменту при обработке литохимических данных приводит к выделению «ложных» ландшафтных или пропуску «продуктивных» слабоконтрастных аномалий. В результате сочетания многофакторного и кластер-анализа, по сути, создан вариант математической модели типологической ландшафтно-геохимической карты. Оперируя классификацией CL-cl достаточно просто формировать выборки литохимических данных при расчете фоновых и аномальных параметров геохимического поля, которые для геоморфологически и геологически различных частей территории могут существенно различаться (рис. 3). В условиях влажного тропического выветривания горных пород процессы гипергенной миграции и накопления химических элементов очень контрастно влияют на геохимические характеристики вторичных ореолов рассеяния продуктов гидротермально-метасоматической деятельности. Только после внесения поправок на выявленные особенности изменчивости геохимического фона удалось получить

\section{СПИСОК ЛИТЕРАТУРЫ}

1. Handbook of exploration geochemistry: in 7 v. V. 4: Regolith exploration geochemistry in tropical and subtropical terrains / Ed. by C.R.M. Butt, H. Zeegers. - Rotterdam: Elsevier, 1992. - 607 p.

2. Перельман А.И., Касимов Н.С. Геохимия ландшафтов. Издание 3-е. - М.: Астрея-2000, 1999. - 768 с.

3. Voicu G., Bardoux M. Geochemical behavior under tropical weathering of the Barama-Mazaruni greenstone belt at Omai gold удовлетворительные литохимические критерии выделения участков гидротермальных изменений пород и вторичных ореолов рассеяния элементов-спутников золотой минерализации. Линейные зоны развития приразломных гидротермалитов картируются в значениях отношений коэффициентов концентраций центростремительных (Ag, $\mathrm{Bi}, \mathrm{As}, \mathrm{Mo}, \mathrm{W})$ и центробежных (Cr, Ni, Th) компонентов золоторудных гидротермальных систем [23-25]. По вторичным ореолам рассеяния известных проявлений золота получена линейная дискриминантная функция (D) для дифференциации по принадлежности к пробам с содержанием $\mathrm{Au} \geq 0,1 \mathrm{ppm}$ :

$$
\mathrm{D}=-38,989+11,452 \mathrm{KKAg}+9,157 \mathrm{KKBi}+4,293
$$

KKMо+2,681 KKW+1,521 KKV-1,41 KKNi-1,143 ККTh.

Геохимический спектр и знаки дискриминационных коэффициентов, с одной стороны, проявляют характерную для орогенных месторождений золота зеленокаменного пояса Барама-Мазаруни пространственную близость к интрузивным телам гранитоидов и тектоническим зонам смятия, с другой стороны, включают элементы, описываемые для этих объектов в составе парагенезиса: $\mathrm{Au}-\mathrm{Ag}-\mathrm{Te}-\mathrm{W}-\mathrm{Bi}-\mathrm{Pb}-\mathrm{Zn}-\mathrm{Cu}-$ $\mathrm{Hg}-\mathrm{Mo}[16,18]$.

\section{Заключение}

Изучение особенностей флуктуации фоновых содержаний химических элементов при поисках месторождений полезных ископаемых по вторичным ореолам рассеяния является важной составляющей процесса выбора геохимических прогнозно-поисковых критериев. Особенно высока актуальность количественной и качественной оценки фоновых параметров геохимического поля в ландшафтах теплого гумидного климата, характеризующихся высокой активностью водной миграции химических элементов. Даже при ограниченном объеме геологической информации методами многофакторного и кластер-анализа литохимических данных удается создать пространственную классификационную модель, близкую по смыслу к ландшафтно-геохимической карте, и осуществить прогноз геологического строения территории.

Авторы выражают искреннюю признательность Виталию Юрьевичу Фомину, Анатолию Алексеевичу Кучеренко, Алексею Алексеевичу Данилову, Игорю Давыловичу Гласс, Андрею Петровичу Зайченко и другим сотрудникам геологической службы ООО «Золотой Запас» за предоставленные геологические материаль, ценные советь и возможность проведения исследований в Республике Гайана.

Исследования поддержань Российским фондом фундаментальных исследований (проект № 18-05-70047).

mine, Guiana Shield // Applied Geochemistry. - 2002. - № 17. P. 321-336.

4. Geochemical sediments and landscapes / Ed. by D.J. Nash, S.J. McLaren. - Singapore: Blackwell Publishing, 2007. - 489 p.

5. Геологическая эволюция и самоорганизация системы водапорода: в 5 т. Т. 2: Система вода-порода в условиях зоны гипергенеза / С.Л. Шварцев, Б.Н. Рыженко, В.А. Алексеев, Е.М. Дутова, И.А. Кондратьева, Ю.Г. Копылова, О.Е. Лепоку- 
рова / отв. ред. тома Б.Н. Рыженко. - Новосибирск: Изд-во СО PAH, 2007. $-389 \mathrm{c}$.

6. Butt C.R.M., Cluzel D. Nickel laterite ore deposits: weathered serpentinites // Elements. - 2013. - V. 9. - P. 123-128.

7. Rare earth element geochemistry during weathering of S-type granites from dry to humid climates of Brazil / Y.J.A.B. da Silva, C.W.A. do Nascimento, C.M. Biondi, P. van Straaten, Y.J.A.B. da Silva // Journal of Plant Nutrition and Soil Science. - 2018. V. 181. - Iss. 6. - P. 938-953.

8. Insights on the paradigms applied for mineral exploration in deeply weathered landscapes / I. González-Álvarez, A.R. King, J. Klump, G. Smith, M. Brønner, S. Pernreiter, T. Ibrahimi // Proc. for the $5^{\text {th }}$ Australian Regolith Geoscientists Association Conference. - Wallaroo, South Australia, Report Book 2018/00011. Adelaide: Department of the Premier and Cabinet, 2018 - P. 6-9.

9. Spier C.A., Levett, A., Rosière C.A. Geochemistry of canga (ferricrete) and evolution of the weathering profile developed on itabirite and iron ore in the Quadrilátero Ferrífero, Minas Gerais, Brazil // Mineralium Deposita. - 2019. - V. 54. - Iss. 7. - P. 983-1010

10. Mazzucchelly R.H. Geochemical exploration in areas affected by tropical weathering // Proceedings of Exploration 97: Fourth Decennial International Conference on Mineral Exploration / Ed. by A.G. Gubins. - Toronto: Prospectors and Developers Association, 1997. - P. 315-322.

11. Eberle D.G., Paasche H. Integrated data analysis for mineral exploration: a case study of clustering satellite imagery, airborne gamma-ray, and regional geochemical data suites // Geophysics. 2012. - V. 77. - № 4. -P. B167-B176.

12. Classifying airborne radiometry data with Agglomerative Hierarchical Clustering: a tool for geological mapping in context of rainforest (French Guiana) / G. Martelet, C. Truffert, B. Tourlie`re, P. Ledru, J. Perrin // International Journal of Applied Earth Observation and Geoinformation. - 2006. - № 8. - P. 208-223.

13. A new interpretation of the geology of British Guiana / R.B. McConnell, E. Williams, R.T. Cannon, N.J. Snelling // Nature. - 1964. - V. 204. - № 4954. - P. 115-118.

14. Докембрий континентов. Северная и Южная Америка А.К. Башарин, Н.А. Берзин, Б.Д. Дворкина, В.Н. Мошкин,
В.И. Шульдинер. - Новосибирск: Изд-во «Наука» Сибирское отделение, 1976. $-239 \mathrm{c}$.

15. Gibbs A.K., Barron C.N. Geology of the Guiana Shield. Oxford Monographs on Geology and Geophysics № 22. - Oxford: Clarendon Press, 1993. -258 p

16. Voicu G., Bardoux M., Stevenson R. Lithostratigraphy, geochronology and gold metallogeny in the northern Guiana Shield, South America: a review // Ore Geology Reviews. - 2001. - № 18. P. 211-236.

17. Tedeschi M., Hagemann S.G., Davis J. The Karouni gold deposit, Guyana, South America: Part I. Stratigraphic setting and structural controls on mineralization // Economic Geology. - 2018. V. 113. - № 8. - P. 1679-1704.

18. Voicu G. Geology, geochemistry and metallogeny of the Omai gold deposit, Guiana Shield, South America. Doct. Diss. - Montreal, 1999. $-297 \mathrm{p}$.

19. Юрьева Ю.С. Коры выветривания и радиогеохимические критерии поисков золота в рудном узле Амамури (Республика Гайана): дис. ... магистра геологии. - Томск, 2018. - 182 с.

20. Макаревич Т.Г. Геологическое строение и проект оценочных работ проявления золота «Контакт»: дис. ... магистра геологии. - Томск, 2018. - $113 \mathrm{c}$.

21. Ткачев Ю.А. Корреляционный анализ в геохимии: три проблемы практического применения // Известия Томского политехнического университета. - 2008. - Т. 312. - № 1. - С. 34-41.

22. Valls R.A. Why, and how, we should use compositional data analysis. A Step-by-step guide for the field geologists. - Toronto, Ontario: Wikibooks, 2008. -58 p.

23. Питулько В.М., Крицук И.Н. Основы интерпретации данных поисковой геохимии. - Л.: Недра, 1990. - 336 с.

24. Соколов В.С. Структуры аномальных геохимических полей и прогноз оруденения. - Спб.: Недра, 1998. - 154 с.

25. Ворошилов В.Г. Аномальные структуры геохимических полей гидротермальных месторождений золота: механизм формирования, методика геометризации, типовые модели, прогноз масштаба оруденения // Геология рудных месторождений. 2009. - T. 51. - № 1. - C. 3-19.

Поступила: 11.11.2019 2.

\section{Информация об авторах}

Соболев И.С., кандидат геолого-минералогических наук, главный геолог ООО «Гео Сервис»; научный сотрудник лаборатории перспективных методов морских исследований Тихоокеанского океанологического института им. В.И. Ильичева ДО РАН.

Соболева Н.П., кандидат географических наук, доцент отделения геологии Инженерной школы природных ресурсов Национального исследовательского Томского политехнического университета. 
UDC 550.8.053, 550.842, 550.84.09

\section{FLUCTUATION ANALYSIS OF CHEMICAL ELEMENTS BACKGROUND VALUES IN LITHOCHEMICAL EXPLORATION UNDER TROPICAL WEATHERING (SOUTH AMERICA, GUYANA)}

Igor S. Sobolev1,2,

geolsob@yandex.ru

Nadezhda P. Soboleva ${ }^{3}$,

sobnadi@yandex.ru

1 LLC «Geo Service»,

5, office 21, Uchebnaya street, Tomsk, 634028, Russia.

2 V.I. Ilichev Pacific Oceanological Institute, Far Eastern Branch, Russian Academy of Sciences,

43, Baltiyskaya street, Vladivostok, 690041, Russia.

3 National Research Tomsk Polytechnic University,

30, Lenin avenue, Tomsk, 634050, Russia.

The relevance of the research is determined by informative improvement of lithochemical exploration on secondary scattering halos under humid tropical weathering. Widespread distribution of large weathering cover leads to limitations in study of basement rocks in natural outcrops. In such cases the role of geochemical methods increases when mapping the basement and exploration of ore deposits localized there. Specific feature of tropical hypergene redistribution of chemical elements is high intensity, general prevalence of removal with parallel accumulation of several components in the laterization process. Combination of these processes results in high variability of geochemical background and appearance of secondary anomalies of some metal elements that are not associated with ore deposits. As a result, landscape-geochemical mapping is very relevant. The mapping allows making the zoning of territories based on components distribution features in elementary landscapes and systematizing the prior factors of geochemical background variability. The values of chemical elements concentration contain data on all natural processes that have affected the composition of the studied material. Therefore, the investigation of lithochemical data by statistical analysis tools allows obtaining a mathematical model in the form of a typological landscapegeochemical map.

The aim of the study is to differentiate the territory on geochemical background variability.

Methods: multivariate factor, correlation and cluster analysis of multi-component data of lithochemical exploration on secondary scattering halos.

Results. We obtained classification model of geochemical background that reflects relations between chemical elements accumulation levels, geomorphology and geology, taking into account the amplitude and spatial characteristics of geochemical field variability in seconddary scattering halos; we also determined trace elements associated with gold mineralization.

\section{Key words:}

Weathering crust, chemical elements, classification model, geology, geomorphology, humid tropics.

The authors express thanks to Vitaly Yu. Fomin, Anatoly A. Kucherenko, Aleksey A. Danilov, Igor D. Glass, Andrey P. Zaychen$k o$ and other employees of geological service of LLC «Zolotoy Zapas» for geological materials, valuable advice and opportunity of research in Guyana.

The research was supported by the Russian Foundation for Basic Research of (project no. 18-05-70047).

\section{REFERENCES}

1. Handbook of exploration geochemistry: in 7 vol. Vol. 4: Regolith exploration geochemistry in tropical and subtropical terrains. Eds. C.R.M. Butt, H. Zeegers. Rotterdam, Elsevier, 1992. 607 p.

2. Perelman A.I., Kasimov N.S. Geokhimiya landshaftov [Landscape geochemistry]. Moscow, Astreya-2000 Publ., 1999. 768 p.

3. Voicu G., Bardoux M. Geochemical behavior under tropical weathering of the Barama-Mazaruni greenstone belt at Omai gold mine, Guiana Shield. Applied Geochemistry, 2002, no. 17, pp 321-336.

4. Geochemical sediments and landscapes. Eds. D.J. Nash, S.J. McLaren. Singapore, Blackwell Publ., 2007. 489 p.

5. Shvartsev S.L., Ryzhenko B.N., Alekseev V.A., Dutova E.M., Kopylova Yu.G., Lepokurova O.E. Geologicheskaya evolyutsiya i samoorganizatsiya sistemy voda-poroda. T. 2: Sistema vodaporoda $v$ usloviyakh zony gipergeneza [Geological evolution and self-organization of the water-rock system. Vol. 2: Water-rock system in a hypergenesis zone]. Ed. by B.N. Ryzhenko. Novosibirsk, Publishing House of the SB RAS, 2007. 389 p.
6. Butt C.R.M., Cluzel D. Nickel laterite ore deposits: weathered serpentinites. Elements, 2013, vol. 9, pp. 123-128.

7. Da Silva Y.J.A.B., Do Nascimento C.W.A., Biondi C.M., Van Straaten P., Da Silva Y.J.A.B. Rare earth element geochemistry during weathering of S-type granites from dry to humid climates of Brazi. Journal of Plant Nutrition and Soil Science, 2018, vol. 181, Iss. 6, pp. 938-953.

8. González-Álvarez I., King A.R., Klump J., Smith G., Bronner M., Pernreiter S., Ibrahimi T. Insights on the paradigms applied for mineral exploration in deeply weathered landscapes. Proceedings for the $5^{\text {th }}$ Australian Regolith Geoscientists Association Conference. Wallaroo, South Australia, Report Book 2018/00011. Adelaide, Department of the Premier and Cabinet, 2018. pp. 6-9.

9. Spier C.A., Levett A., Rosière C.A. Geochemistry of canga (ferricrete) and evolution of the weathering profile developed on itabirite and iron ore in the Quadrilátero Ferrífero, Minas Gerais, Brazil. Mineralium Deposita, 2019, vol. 54, Iss. 7, pp. 983-1010. 
10. Mazzucchelly R.H. Geochemical exploration in areas affected by tropical weathering. Proceedings of Exploration 97: Fourth Decennial International Conference on Mineral Exploration. Ed. by A.G. Gubins. Toronto, Prospectors and Developers Association, 1997. pp. 315-322.

11. Eberle D.G., Paasche H. Integrated data analysis for mineral exploration: a case study of clustering satellite imagery, airborne gamma-ray, and regional geochemical data suites. Geophysics, 2012, vol. 77, no. 4, pp. B167-B176.

12. Martelet G., Truffert C., Tourlie`re B., Ledru P., Perrin J. Classifying airborne radiometry data with Agglomerative Hierarchical Clustering: a tool for geological mapping in context of rainforest (French Guiana). International Journal of Applied Earth Observation and Geoinformation, 2006, no. 8, pp. 208-223.

13. McConnell R.B., Williams E., Cannon R.T., Snelling N.J. A new interpretation of the geology of British Guiana. Nature, 1964, vol. 204, no. 4954, pp. 115-118.

14. Basharin A.K., Berzin N.A., Dvorkina B.D., Moshkin V.N., Schuldiner V.I. Dokembriy kontinentov. Severnaya i Yuzhnaya Amerika [Pre-Cambrian continents. North and South America]. Novosibirsk, Nauka Publ. house, Siberian Branch, 1976. 239 p.

15. Gibbs A.K., Barron C.N. Geology of the Guiana Shield. Oxford Monographs on Geology and Geophysics no. 22. Oxford, Clarendon Press, 1993. 258 p.

16. Voicu G., Bardoux M., Stevenson R. Lithostratigraphy, geochronology and gold metallogeny in the northern Guiana Shield, South America: a review. Ore Geology Reviews, 2001, no. 18, pp. 211-236.

17. Tedeschi M., Hagemann S.G., Davis J. The Karouni gold deposit, Guyana, South America: P. I. Stratigraphic setting and structural controls on mineralization. Economic Geology, 2018, vol. 113, no. 8, pp. 1679-1704.
18. Voicu G. Geology, geochemistry and metallogeny of the Omai gold deposit, Guiana Shield, South America. Dr. Diss. Montreal, 1999. $297 \mathrm{p}$.

19. Yurieva Yu.S. Kory vyvetrivaniya i radiogeokhimicheskie kriterii poiskov zolota v rudnom uzle Amamuri (Respublika Gayana). Diss. magistra [Weathering crusts and radio-geochemical criteria for gold prospecting in the Amamuri ore cluster (Republic of Guyana). Master's Diss.]. Tomsk, 2018. 182 p.

20. Makarevich T.G. Geologicheskoe stroenie i proekt otsenochnykh rabot proyavleniya zolota «Kontakt». Diss. magistra [Geology and the prospect project of the «Contact» gold occurrence. Master's Diss.]. Tomsk, 2018. 113 p.

21. Tkachev Yu.A. Correlation analysis in geochemistry: three problems of practical application. Bulletin of the Tomsk Polytechnic University, 2008, vol. 312, no. 1, pp. 34-41. In Rus.

22. Valls R.A. Why, and how, we should use compositional data analysis. A Step-by-step guide for the field geologists. Toronto, Ontario, Wikibooks, 2008. $58 \mathrm{p}$

23. Pitulko V.M., Kritsuk I.N. Osnovy interpretatsii dannykh poiskovoy geokhimii [Basics of geochemistry exploration data interpretation]. Leningrad, Nedra Publ., 1990. 336 p.

24. Sokolov V.S. Struktury anomalnykh geokhimicheskikh poley $i$ prognoz orudeneniya [Structures of abnormal geochemical fields and ore mineralization forecast]. St. Petersburg, Nedra Publ., 1998. $154 \mathrm{p}$.

25. Voroshilov V.G. Anomalous structures of geochemical fields of hydrothermal gold deposits: formation mechanism, methods of geometrization, typical models, and forecasting of ore mineralization. Geology of ore deposits, 2009, vol. 51, no. 1, pp. 3-19. In Rus.

Received: 11 November 2019.

\section{Information about the authors}

Igor S. Sobolev, Cand. Sc., chief geologist, LLC «Geo Service»; researcher, V.I. Ilichev Pacific Oceanological Institute, Far Eastern Branch, Russian Academy of Sciences.

Nadezhda P. Soboleva, Cand. Sc., associate professor, National Research Tomsk Polytechnic University. 